Original research article

\title{
Contributory role of ART in the development of non-AIDS comorbidities in asymptomatic PLWHA
}

\author{
Karen Ingrid Tasca ${ }^{1 *}$, Vânia V. M. Fagundes Vidal ${ }^{2}$, Vanessa Martinez Manfio ${ }^{3}$, \\ Alexandre Naime Barbosa ${ }^{2,3}$, Lenice do Rosário de Souza ${ }^{2,3}$ \\ ${ }^{1}$ São Paulo State University - UNESP, Institute of Biosciences of Botucatu, Department of Microbiology and Immunology, Botucatu, São Paulo State, \\ Brazil \\ 2 Specialist Outpatient Service for Infectious Diseases "Domingos Alves Meira” (SAEI-DAM), Botucatu, São Paulo State, Brazil \\ ${ }^{3}$ São Paulo State University - UNESP, Botucatu Medical School, Department of Tropical Diseases and Imaging Diagnosis, Botucatu, São Paulo State, \\ Brazil
}

\begin{abstract}
Background: Despite the many benefits that follow antiretroviral therapy (ART) initiation, its chronic use contributes to the early aging of people living with HIV/AIDS (PLWHA). The aim of this cross-sectional study was to trace the prevalence of and investigate possible renal, bone and metabolic changes, as well as cardiovascular risk in 94 asymptomatic PLWHA, relating them to the duration of ART use. Methods: Four groups were evaluated according to ART use: G1 $(n=21)$, ART-naïve individuals; G2 $(n=17),<2$ years; G3 $(n=40)$, 2-10 years; and G4 ( $n=16)$ on ART for more than 10 years.

Results: Our results showed a high prevalence of dyslipidemic individuals (64\%), especially in those under ART. Lower creatine phosphokinase levels were observed in G1 as compared to the others $(p<0.05)$. Regarding the Framingham score, 12.1\% of PLWHA showed moderate and high risk, and the highest proportion $(38.5 \%)$ occurred in $\mathrm{G} 4(p=0.003)$. A decrease in glomerular filtration rates occurred in $20 \%$ of patients, which was also more significant in G3 and G4 ( $p=0.007)$. High prevalences of osteopenia and osteoporosis (53.2\%) were found, especially in G1 and G4; however, G1 showed the lowest means for alkaline phosphatases (AP, $p=0.04$ and BAP, $p=0.005)$ and osteocalcin $(p=0.005)$, in addition to higher vitamin-D concentrations $(p=0.04)$.

Conclusions: Our study showed the possible contributory role of ART in these changes, which leads us to reflect on the need for specific conducts and patient care, pointing out the importance of individualized care in an attempt to increase life expectancy.
\end{abstract}

Keywords: Antiretroviral; Dyslipidemia; HIV/Aids; Non-AIDS comorbidities

\section{Highlights:}

- The chronic use of ART compromises metabolic, hepatic, bone and renal function.

- There is a higher risk of cardiovascular event (Framingham score) in patients on ART for more than 10 years.

- Bone changes can be observed in ART-naïve patients, showing the direct role of HIV in such disturbances.

\section{Introduction}

Today, with the access to antiretroviral therapy (ART) and good health care, the life expectancy of a person living with HIV/AIDS (PLWHA) is very similar to that of the general population. According to the World Health Organization, expanding access to treatment ("test-and-treat" strategy) is one of the three main goals set for 2020, with the aim of controlling the AIDS epidemic as a threat to public health by 2030 (UNAIDS, 2019).

Despite the unquestionable long-term advantages of ART, early intervention has shown not only clinical benefits and, in this context, new challenges are present. Looking at the cause of PLWHA deaths today, there is a great occurrence (with an earlier onset) of typical diseases of aging such as ischemic heart disease, stroke and other central nervous system disorders, dyslipidemia, liver disease, chronic kidney disease (CKD), diabetes mellitus (DM), bone changes and non-AIDS-related cancers (d'Arminio et al., 2019; Deeks, 2011; Guaraldi et al., 2011; Smith et al., 2014; Suligoi et al., 2018). This phenomenon, known as "premature aging", is a reflection not only of the adverse effects of therapy, but also of the persistent inflammatory process resulting from constant replication of HIV, even when it is residual, as in asymptomatic individuals (d'Arminio et al., 2019; Deeks, 2011; Guaraldi et al., 2011; Smith et al., 2014; Suligoi et al., 2018).

In PLWHA, the finding of osteopenia and osteoporosis is common, with an estimated prevalence three times as high as that in individuals without the virus (Brown and Qaqish,

\footnotetext{
* Corresponding author: Karen Ingrid Tasca, Lab. de Imunomodulação por Produtos Naturais, Instituto de Biociências de Botucatu (IBB-UNESP) - Departamento de Microbiologia e Imunologia, R. Prof. Dr. Antônio Celso Wagner Zanin 250, Botucatu, SP, Brazil. Cep: 18618-689; e-mail: karenitasca@hotmail.com; http://doi.org/10.32725/jab.2021.002

Submitted: 2020-04-27 • Accepted: 2021-01-21 • Prepublished online: 2021-01-27

J Appl Biomed 19/1: 73-82 • EISSN 1214-0287 • ISSN 1214-021X

(c) 2021 The Authors. Published by University of South Bohemia in České Budějovice, Faculty of Health and Social Sciences.

This is an open access article under the CC BY-NC-ND license.
} 
2006). In addition to known risk factors, such as chronic alcohol use and smoking, hormonal disorders, low body weight, vitamin-D deficiency, corticosteroid use and lack of exercise, both HIV infection and ART use, regardless of the antiretroviral regimen, also contribute to the reduction of bone mineral density (BMD), especially the use of tenofovir (Bolland et al., 2006; Bonjoch et al., 2010; Brown et al., 2009).

During effective ART, CKD has also gained prominence due to its much higher prevalence in PLWHA, with rates close to $8 \%$, while in the general population such rates are only seen in people over 60 years old (Lugon, 2009; Menezes et al., 2011). Classically, the main factors associated with increased risk for CKD are age over 60 years, ethnicity (African descendants, Hispanics, Asians and Indians), female gender, low body weight, family history of CKD, diabetes mellitus, metabolic syndrome (including dyslipidemia), recurrent urinary infections, cardiovascular disease, systemic arterial hypertension, smoking and obesity. In PLWHA, other potential factors are longer HIV infection, longer ART use, presence of tenofovir, indinavir and atazanavir in the treatment regimen, low CD4+ T lymphocyte count and presence of opportunistic infections (Déti et al., 2010; Lugon, 2009; Menezes et al., 2011; Mocroft et al., 2007).

Regarding the risk for cardiovascular disease, longer ART use, especially that containing abacavir and protease inhibitors (PI), seems to increase the risk for myocardial infarction (Dorjee et al., 2018; Friis-Møller et al., 2003; Worm et al., 2010). The study Data Collection on Adverse Events of Anti-HIV Drugs showed that the relative increase in risk for myocardial infarction was $26 \%$ per year of drug exposure (Friis-Møller et al., 2003). Again, one factor contributing to these high rates is metabolic syndrome as a consequence of antiretroviral use, including dyslipidemia, insulin resistance, overweight and obesity (Wand et al., 2007).

Thus, this study aimed to investigate in PLWHA, both in treatment-naïve and in those on ART and with adequate viral suppression (undetectable HIV plasma viral load (VL), the prevalence of non-AIDS comorbidities, especially renal, bone and metabolic changes and cardiovascular risk and the relationship of such alterations with the length of time of ART use.

\section{Material and methods}

\section{Study design}

This cross-sectional study was conducted from 2014 to 2018 at the Specialized Outpatient Service for Infectious Diseases "Domingos Alves Meira" (SAEI-DAM) - Botucatu Medical School Complex (FMB)-UNESP, in São Paulo state, Brazil. The convenience sample totaled 94 HIV-infected adults included in the study, divided into four groups according to the duration of ART use: G1 $\rightarrow$ ART-naive $(n=21)$; G2 $\rightarrow$ on ART for less than two years $(n=17)$; G3 $\rightarrow$ on ART for two to 10 years $(n=40)$; G4 $\rightarrow$ on ART for more than 10 years $(n=16)$.

\section{Inclusion and exclusion criteria}

The patient inclusion criteria were age between 18 and 50 years, signing an informed consent form and belonging to a study group, as mentioned above. As to the individuals in the ART groups, only those who had an undetectable viral load at the time of inclusion were included.

Those with a cancer history (current or previous), anorexia, morbid obesity, diabetes mellitus, cardiovascular, genetic or autoimmune diseases, organ transplants, pregnancy, coinfections such as tuberculosis, chronic viral hepatitis, cerebral or disseminated toxoplasmosis, and use of illicit drugs or alcohol were excluded.

\section{Sociodemographic and clinical data}

The complementary data (sociodemographic factors, metabolic and biochemical tests and HIV viral load (VL) quantifications) were collected from electronic medical records relative to the date of blood collection for this study.

\section{Laboratory tests}

$12 \mathrm{ml}$ of blood was collected and centrifuged at 1,500 rpm for $10 \mathrm{~min}$. Some plasma aliquots per individual were stored at $-80{ }^{\circ} \mathrm{C}$ until all the assays were conducted at the Tropical Diseases Laboratory of the Botucatu Medical School (FMB/ UNESP), Flow Cytometry and Molecular Biology Laboratories at the Botucatu Blood Center and Clinical Analyses Laboratory, both belonging to the Botucatu University Hospital (FMB/ HC), SP, Brazil.

Analysis of bone changes

- Osteocalcin (OC) and bone alkaline phosphatase (BAP): MicroVue Osteocalcin EIA (enzyme immunoassay) kit and MicroVue BAP ELISA - QUIDEL ${ }^{\circledR}$ (USA, CA, San Diego).

- Collagen type-I carboxyterminal telopeptide (s-CTX): Cross Linked C-telopeptide of type-I collagen, ELISA kit ELABSCIENCE (USA).

- 25-OH vitamin D: 3L52 ARCHITECT 25-OH Vitamin-D kit, an immunoassay of microparticles by chemiluminescence (CMIA).

- Dual emission x-ray absorptiometry (DXA): Dual-Energy $X$-Ray Absorptiometry, in a Hologic Discovery-A device, is the test that evaluates bone mineral density and risk for fracture. It is considered gold standard for osteoporosis diagnoses. The results were interpreted under two aspects, that is, by comparison with data from individuals at the same age group and with similar bone mineral density. They were also classified according to WHO consensus (Kanis et al., 2008).

- Fracture Risk Assessment Tool (FRAX): It is an epidemiological index developed to combine the various risk factors for osteoporotic fracture, which enables the calculation of the absolute risk for fracture in 10 years, thus identifying high-risk patients (Kanis, 2007; Kanis et al., 2008).

\section{Renal function analysis}

- Calculation of the glomerular filtration rate (GFR): GFR was calculated concomitantly by the three most commonly used serum estimation formulas as recommended by nephrology societies: Cockcroft-Gault, MDRD and CKD-EPI. In order to simplify calculations and avoid errors, we used an electronic application made available by the National Kidney Foundation (2011), which makes it possible to enter data and obtain results automatically. For CKD-EPI score categorization, the following stages were considered: 1 : 290; 2 : 60-89; 3: 30-59; 4: 15-29; 5: <15 ml/min/1.73 $\mathrm{m}^{2}$ or dialysis.

\section{Cardiovascular disease risk assessment}

- Framingham Score: the scores 1, 2 and 3 were used to assess the risk for cardiovascular events in 10 years. The risk can be considered low $(<10)$, moderate $(10-20)$ or high (>20) respectively (Wilson et al., 1998). 
Assessment of inflammatory status and metabolic disorders

- Creatinophosphokinase (CPK), lactic dehydrogenase (LDH) and C-reactive protein (CRP), erythrocyte sedimentation rate (ESR), creatinine, urea and parathormone (PTH), total cholesterol and fractions (high-density lipoprotein, HDL and low-density lipoprotein, LDL), triglycerides (TG), glucose, body mass index (BMI): results were collected from electronic medical records. Dyslipidemia was considered when the subject had isolated hypercholesterolemia (LDL > $160 \mathrm{mg} / \mathrm{dl}$ ), isolated hypertriglyceridemia (TG >150 mg/dl) or low HDL ( $<40$ or $<50 \mathrm{mg} / \mathrm{dl}$, if male or female, respectively) (Faludi et al., 2017).

\section{Analysis of results}

Statistical analysis was performed respecting the assumptions determined by the results, characteristics and behavior of the study variables. Thus, considering the continuous variables and using the Shapiro-Wilk test to analyze normality, the following tests were applied: for non-parametric variables, Gamma Distribution or Kruskal-Wallis; for parametric variables, Multiple Comparisons (ANOVA) followed by Tukey's Test. Considering the categorical variables, association tables and Chi-square were analyzed. Significant differences were considered when $p$ values were less than or equal to 0.05 . All these procedures were performed with help from professionals at the institution's Research Support Office using SAS for Windows, version 9.2.

\section{Results and discussion}

\section{Sociodemographic and clinical data}

The sociodemographic, clinical and therapeutic characterization of the studied PLWHA is shown in Supplemental Digital Content. Of the 94 patients included, most were male $(n=50,53.2 \%)$, white $(n=75,79.8 \%)$ and had a mean age of $37 \pm 9$ years. The groups were homogeneous as regards gender, skin color, smoking habits, social drinking, use of other medications in addition to antiretrovirals and physical activity ( $p>0.05)$. Considering age, gender and skin color, our data were in accordance with data reported in Brazil in 2019, where most cases of HIV infection were in the range of 20 to 34 years, $69 \%$ were male and $40.9 \%$ were white people (Brasil, MS, 2019).

However, the groups were heterogeneous as to the mean age of their members, with G4 being composed of older people, which was expected considering that these patients had been on ART for more than 10 years. Other differences found between the groups were related to the time since diagnosis and the number of changes in ART regimens, which were both also greater in $\mathrm{G} 4$.

At the time of diagnosis, G1 showed a lower CD4+ T lymphocyte count than the other groups and VL above the detection limit for the majority (95.2\%) of the individuals. The conditions shown by such individuals portrayed a recent diagnosis of the infection because blood collection was performed in the pre-treatment period, considering that the beginning of ART is immediate after diagnosis confirmation in Brazil, according to current recommendations by the Ministry of Health (Brasil, MS, 2018). For most individuals, VL is expected to become undetectable and T CD4+ counts will increase considerably after six months of treatment, as shown by a study by our group, published in 2013 (Fukumoto et al., 2013).

\section{Metabolic variables}

HIV infection alone already changes the metabolic profile of patients, and it is associated with a reduction in lipid levels, weight loss and protein depletion. But these levels rise in the long term, with the initiation and maintenance of ART (Mgogwe et al., 2012; Pinto Neto et al., 2013; Young et al., 2005). Even after therapy initiation, it is observed that $33.0 \%$ to $82.0 \%$ of patients develop hypercholesterolemia and $43.0 \%$ to $66.0 \%$ hypertriglyceridemia (Brasil, MS, 2008). These are changes that mainly contribute to the development of cardiovascular diseases (Balloca et al., 2017). In our study, considering all patients, these prevalences were lower, at $5.3 \%$ and $33.0 \%$ respectively, being more frequent in the groups under ART, than in the naïve group. However, when also considering low HDL values, we had more than $60.0 \%$ of dyslipidemics. Fig. 1A shows the following prevalence of dyslipidemia by group: $38.1 \%$ in $\mathrm{G} 1,88.2 \%$ in $\mathrm{G} 2,75.0 \%$ in $\mathrm{G} 3$ and $60 \%$ in $\mathrm{G} 4$.

The means for glucose, total cholesterol, HDL, LDL and TG are shown in Fig. 1B. We found that total cholesterol levels were higher in G4 than in G1. These findings have been corroborated by other studies (Pinto Neto et al., 2013; Souza et al., 2013; Vos et al., 2018), indicating that ART actually has a role in changing the metabolic profile of patients, and this action is enhanced with years of therapy (Pinto Neto et al., 2013; Vos et al., 2018). It was even possible to observe here a positive correlation between total cholesterol and ART duration $(p=0.001)$. However, it is noteworthy that this association may have an influence on age and time since HIV diagnosis, variables that were also positively correlated with total cholesterol levels ( $p=$ 0.002 and $p=0.007$, respectively).

Souza et al. (2013) showed, in a review study, that metabolic changes vary according to the therapeutic regimen. Most individuals on therapy for the longest time had been using regimens containing PI and, therefore, this is another fact that is related to a greater metabolic disorder (Brasil, MS, 2018). Thus in this study, there was an association between PI use and higher means of total cholesterol $(p=0.003)$, TG $(p=0.029)$ and HDL ( $p=0.018)$. Instead, Hidalgo et al. (2018) found that, in clinically stable middle-aged adults receiving predominantly initial NRTI-based ART, a high proportion of metabolic comorbidities was found, with dyslipidemia, obesity and type-2 DM being the most frequent, and there was also an association of these disorders with the longest duration of ART and older age. However, in general the HDL mean also increased in G4. When our results were categorized, a high proportion (45.7\%) of individuals showed HDL below normality parameters, especially those ART naïve. Increase in HDL may occur after the introduction of ART, resulting in a cardioprotective effect; however, the other lipid fractions also increase (Dai et al., 2019), which enhances the risk for metabolic syndrome. In fact, the SMART study found a decrease in HDL levels after NRTI interruption, which was associated with increased cardiovascular risk (Duprez et al., 2009).

Additional parameters were collected (Table 1) for a more complete biochemical analysis.

CRP, a protein that in high blood concentration indicates inflammatory or infectious processes, along with IL-6, is related to the progression of HIV/AIDS infection (Neaton et al., 2010). In this study, there was no difference in CRP levels between the groups (Table 1), whose means were within normal limits. However, in a previous study carried out by our group (Tasca et al., 2016), there was an increase in CRP in the first six months after the introduction of ART. Considering these two findings, we suggest that a transient alteration of this marker 
A

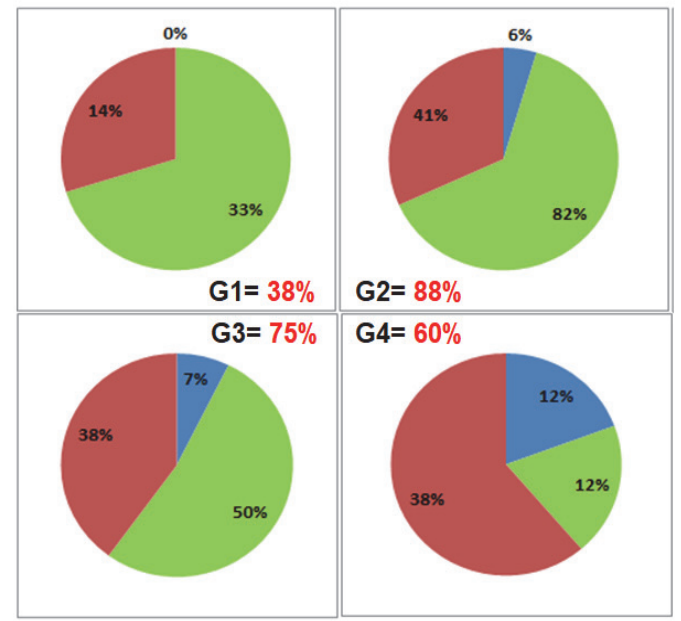

$\square \mathrm{HDL}<40.50 \mathrm{mg} / \mathrm{dL} \quad$ Triglycerides $>150 \mathrm{mg} / \mathrm{dL} \quad \mathrm{LDL}>160 \mathrm{mg} / \mathrm{dL}$
B

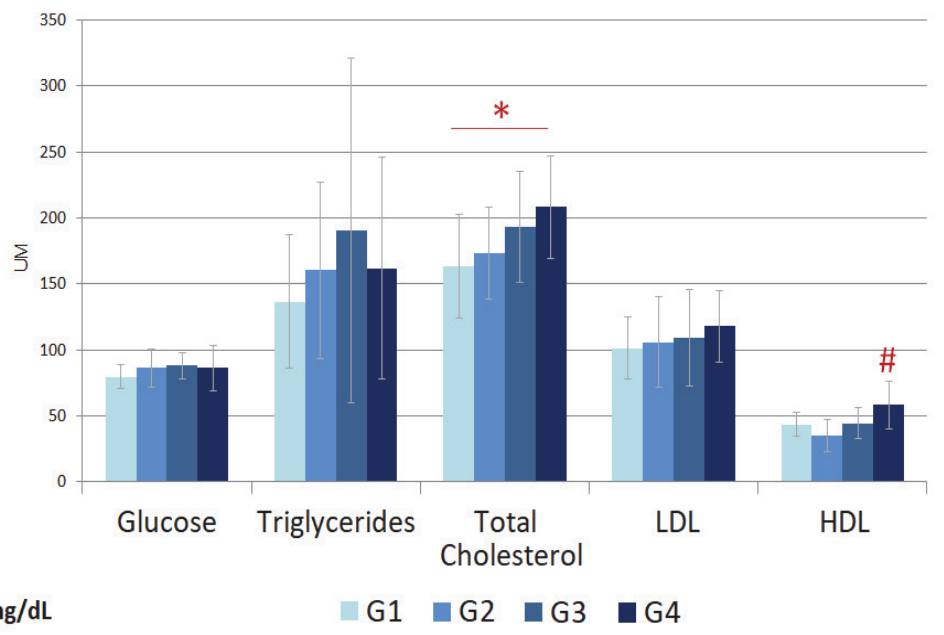

Fig. 1. Metabolic parameters analyzed in different PLWHA groups. (A) frequency (\%) of specific altered exams (HDL, LDL and Triglycerides) that the dyslipidemics presented and global frequency of dyslipidemia in G1 (38\%), G2 (88\%), G3 (75\%) and G4 (60\%); (B) means and standard deviations of the analyzed markers by group. PLWHA: People living with HIV/AIDS; G1: PLWA antirretroviral therapy (ART)-naïve; G2: PLWHA under ART for less than 2 years; G3: PLWHA under ART for 2 to 10 years; G4: PLWHA on ART for more than 10 years. HDL: High Density Lipoprotein; LDL: Low Density Lipoprotein; Dyslipidemia was considered when the subject had isolated hypercholesterolemia (LDL > $160 \mathrm{mg} / \mathrm{dl}$ ), isolated hypertriglyceridemia (TG $>150 \mathrm{mg} / \mathrm{dl}$ ) or low HDL ( $<40$ or $<50 \mathrm{mg} / \mathrm{dl}$, if male or female, respectively). In this sense, the overall percentage of dyslipidemia by group is not the same as shown in the pizza chart because some individuals had mixed dyslipidemia. Statistical test used: Multiple Comparison (ANOVA) followed by Tukey-Kramer post hoc tests; ${ }^{*} p=0.035$ $(\mathrm{G} 1 \neq \mathrm{G} 4) ; \# p=0.023(\mathrm{G} 1 \neq \mathrm{G} 4) ;<0.0001(\mathrm{G} 2 \neq \mathrm{G} 4) ; 0.006(\mathrm{G} 3 \neq \mathrm{G} 4)$.

Table 1. Biochemical examinations of the studied PLWHA

\begin{tabular}{|c|c|c|c|c|c|c|c|c|c|}
\hline & \multicolumn{2}{|c|}{$\mathrm{G} 1(n=21)$} & \multicolumn{2}{|c|}{$\mathrm{G} 2(n=17)$} & \multicolumn{2}{|c|}{ G3 $(n=40)$} & \multicolumn{2}{|c|}{$\mathrm{G} 4(n=16)$} & \multirow[b]{2}{*}{$p$ value } \\
\hline & $\mathrm{ME}$ & SD & $\mathrm{ME}$ & SD & $\mathrm{ME}$ & SD & $\mathrm{ME}$ & SD & \\
\hline CRP (mg/dl) & 0.7 & 0.4 & 0.8 & 0.5 & 0.8 & 0.4 & 0.7 & 0.3 & NS \\
\hline CPK (U/1) & 110.9 & 53.2 & 120.0 & 128.9 & 130.7 & 153.8 & 213.5 & $276.5^{*}$ & $\begin{array}{c}0.0273^{\mathrm{G} 1} \\
0.041^{\mathrm{G} 2} \\
<0.067^{\mathrm{G} 3}\end{array}$ \\
\hline LDH (U/l) & 506.1 & $145.1^{*}$ & 472.3 & 86.9 & 435.5 & 78.7 & 433.9 & 89.2 & $0.0469^{\mathrm{G} 3}$ \\
\hline
\end{tabular}

PLWHA: People living with HIV/AIDS; G1: PLWA antirretroviral therapy (ART)-naïve; G2: PLWHA under ART for less than 2 years;

G3: PLWHA under ART for 2 to 10 years; G4: PLWHA on ART for more than 10 years. ME: Mean; SD: Standard Deviation; CRP: C-reactive protein; CPK: Creatinophosphokinase; LDH: Lactic Dehydrogenase; NS: Not Significant. Statistical test used: Multiple Comparison (ANOVA) followed by Tukey-Kramer post hoc tests to "CRP"; Gamma Distribution for the other variables; $p$ values and the specified groups are being compared with the average of the group that presents the asterisk $\left(^{*}\right)$.

may occur in the initial months of ART, with later normalization. This explanation can be corroborated by Bestawros et al. (2015), who found a decrease in CRP levels after one year of ART, despite remaining at relatively higher levels than in the uninfected population.

In this study, there was no correlation between LDH levels and ART duration $(p=0.075)$, with the highest mean found in G1, as compared to G4. This observation may reflect another association found here, between increased LDH and NRTI use ( $p=0.025)$, which was most frequently observed in G1. In addition, Ramana et al. (2013) found a reduction in LDH after three to six months of ART use. Additionally, it was possible to observe a positive correlation between LDH with aspartate and alanine aminotransferases (AST, $p<0.0001$; ALT, $p=0.02$ ). Among other common causes of increased LDH are Pneumocystis infection, acute myocardial, lung and kidney infarction, hepatitis, alcoholism, acute pancreatitis, bone fractures and intestinal obstruction. Few studies address this parameter in the evolution of HIV infection or of diseases associated with AIDS or not. Therefore, its use as an inflammatory marker still needs to be better clarified.

In our study, the mean CPK concentrations appeared to increase according to ART duration because G4 had higher results than did the other groups. We observed a positive correlation between CPK and ART duration $(p=0.029)$, TG $(p=0.023)$ and total cholesterol $(p=0.013)$. CPK is an enzyme that acts mainly on muscle tissues, including the heart and brain, and its dosage is necessary to investigate possible damage to these organs. However, elevated CPK levels and myopathies have been associated with the use of raltegravir (Madeddu et al., 2015a). In this study, only three (3.2\%) patients were using this specific drug, all belonging to $\mathrm{G} 4$, but it was not possible to observe a correlation between its use and CPK means ( $p=0.490)$. Therefore, further studies on the longterm effects of this class of drugs should be performed, considering that currently, the use of integrase inhibitors is indicated 
as a first-line regimen in Brazil (Brasil, MS, 2018) and in other countries.

\section{Cardiovascular diseases}

Dyslipidemia, insulin resistance and cardiovascular diseases are the most frequent side effects occurring in people using ART (Brasil, MS, 2018; Pinto Neto et al., 2013; Souza et al., 2013; Vos et al., 2018). As previously shown, more than $60.0 \%$ of our patients had dyslipidemia, with a greater proportion in the ART groups, which leads us to suggest greater cardiovascular risk in these groups. In addition, the virus itself appears to have a direct action on the circulatory system, including the systemic, pulmonary arterial wall and the myocardium (Faludi et al., 2017; Hajjar et al., 2005). With this regard, in an ARTnaïve Italian cohort followed for 10 years, the percentage of people in the high-risk group for the Framingham score more than tripled (from $13.0 \%$ to $45.0 \%$ ), which points to the likely effect of aging and HIV infection, as well as this interaction (d'Arminio et al., 2019).

Egger et al. (2001) also used this score to assess cardiovascular risk in ART patients and the main causes of risk were age, gender, smoking and even ART use. In our study, the increase in this score was also clear according to the length of therapy use (Fig. 2). In the general analysis of patients and considering the categorization of risk into low, moderate and high, $12.1 \%$ had moderate- and high-risk scores, the highest proportion being found in G4 (G1: 6.2\%; G2: 0\%; G3: $9.5 \%$ and G4: $38.5 \%)$. Observational studies have shown high rates of acute myocardial infarction or other coronary diseases in PLWHA versus healthy individuals, with the risk of these events being approximately twice as high in those on ART as compared to treatment naïves (Bergersen et al., 2004; Triant, 2013).
A

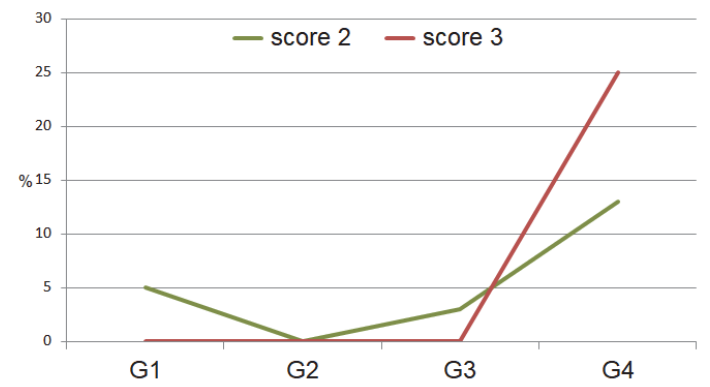

B

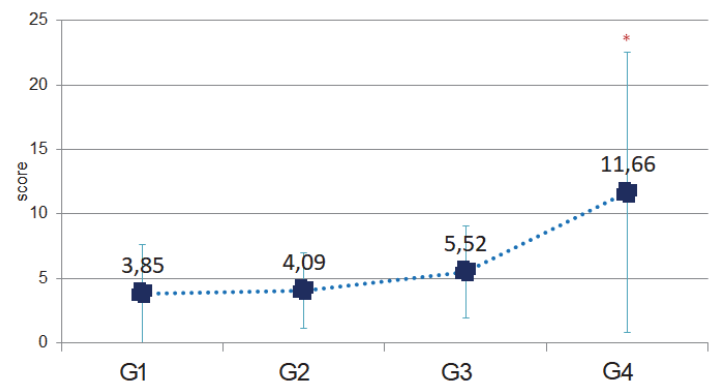

Fig. 2. Framingham score of the studied PLWHA. (A) percentage of people with middle (score 2) and high risk (score 3 ) of cardiovascular events by group; (B) average score by group. PLWHA: People living with HIV/AIDS; G1: PLWA antirretroviral therapy (ART)-naïve; G2: PLWHA under ART for less than 2 years; G3: PLWHA under ART for 2 to 10 years; G4: PLWHA on ART for more than 10 years. Framingham Score: Risk of Development of Cardiovascular Event in 10 years - Low (score 1; <10 points); Moderate (score 2; 10-20 points) and High (score 3; >20 points). Statistical test used: Gamma Distribution; * $p=0.003$ (G1; G2); 0.011 (G3).

However, it is known that the physiology of cardiovascular diseases in this population is complex, involving factors related to both ART and HIV infection itself, as well as traditional risk factors (hypertension, dyslipidemia and diabetes), behavioral (lifestyle), those involving the organism's physiology (age) and genetics (Balloca et al., 2017; Palella and Phair, 2011). In this study, the risk for cardiovascular events was directly correlated, not only with the use or not of ART $(p=0.005)$, but with the length of therapy use $(p=0.0003)$, time of HIV infection $(p<0.0001)$, older age $(p=0.001)$, high glucose values $(p=0.002)$, total cholesterol ( $p=0.031)$, LDL $(p=0.027)$ and NRTI use $(p=0.050)$. Thus, a recent study showed that, although PIs promote more metabolic changes, non-nucleoside reverse-transcriptase inhibitors (NNRTI) use was more frequent in relation to deaths from cardiovascular diseases in a large cohort in the Asia-Pacific region, with the associated factors being advanced age, high blood pressure and high TG, total cholesterol and BMI values (Bijker et al., 2019).

In another study (Krikke et al., 2018), the change from PI to raltegravir slightly reduced endothelial function as well as plasma lipids, possibly decreasing the risk for coronary heart disease in the long term, despite the transient elevation of ALT. As for NRTIs, it has also been shown that the use of abacavir (Dorjee et al., 2018) and tenofovir (Mocroft et al., 2007) increases the risk for these diseases. Maraviroc led to significant improvements in several cardiovascular risk markers, such as endothelial dysfunction, arterial stiffness and early carotid atherosclerosis, which was accompanied by increased vascular competence, without appearing to affect systemic inflammation (Francisci et al., 2019).

\section{Kidney diseases}

In times of effective ART, CKD has also gained prominence as an entity of much higher prevalence in PLWHA, with rates ranging from $4.0 \%$ to $9.0 \%$, while in the general population, these rates are only seen in people over 60 years (Crum-Cianflone et al., 2010; Menezes et al., 2011; Mocroft et al., 2007).

Following the criteria adopted by the National Kidney Foundation (CKD-EPI - Chronic Kidney Disease Epidemiology Collaboration) (2011), the prevalence of reduced renal function (or stage 3 , eGFR $<60 \mathrm{ml} / \mathrm{min} / 1.73 \mathrm{~m}^{2}$ ) in the population studied here was $3 \%$, with these patients belonging to G3. Similarly, a study on other Brazilian HIV cohort by Bonotto et al. (2016), obtained a prevalence of $3.5 \%$ in patients with approximately 10 years of infection and ART use. Mocroft et al. (2007), in a cohort of HIV-positive individuals from 31 countries in Europe, Israel and Argentina found a prevalence of $4.5 \%$. In this study, the overall prevalence of slightly reduced kidney function (stage 2, eGFR $60-89 \mathrm{ml} / \mathrm{min} / 1.73 \mathrm{~m}^{2}$ ) was $17.0 \%$ $(n=16)$, a rate slightly lower than that found by Cristelli et al. (2018), 25\% in adult Spanish individuals on ART. However, in our study, a much higher prevalence was found in patients on ART for many years, and the following frequencies were found, according to the study groups: $9.5 \%$ in $\mathrm{G} 1,11.8 \%$ in $\mathrm{G} 2,12.5 \%$ in $\mathrm{G3}$ and $43.7 \%$ in G4 (Fig. 3). 


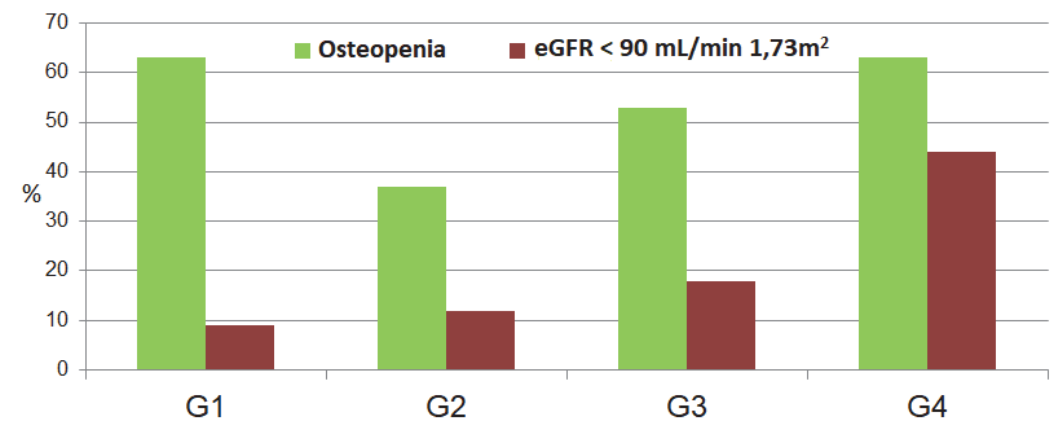

Fig. 3. Frequency of PLWHA with bone and renal changes. PLWHA: People living with HIV/AIDS; G1: PLWA antirretroviral therapy (ART)naïve; G2: PLWHA under ART for less than 2 years; G3: PLWHA under ART for 2 to 10 years; G4: PLWHA on ART for more than 10 years.

In addition, authors reported that the factors associated with the risk for CKD were longer HIV infection, longer ART use, tenofovir use and association with diabetes (Mocroft et al., 2007). In our study, worse renal function was associated with ART use $(p=0.009)$, longer therapy $(p<0.0003)$ and long infection $(p=0.004)$, in addition to higher glucose $(p=0.044)$ and TG $(p=0.005)$ levels and older age $(p=0.001)$.

The means for creatinine, urea and GFR found in this study are shown below, in Table 2. Urea was positively correlated with the time since diagnosis $(p=0.013)$ and length of ART $(p=0.027)$.

However, the risk factors associated with mild renal impairment have been poorly studied in HIV-infected patients and, due to the asymptomatic character of this condition, patients are often not recognized as having kidney disease and, therefore, early interventions, such as ART change and comorbidity treatment, are not usual.

Table 2. Renal and Bone changes presented by the studied PLWHA

\begin{tabular}{|c|c|c|c|c|c|}
\hline & $\mathrm{G} 1(n=21)$ & $\mathrm{G} 2(n=17)$ & $\mathrm{G} 3(n=40)$ & $\mathrm{G} 4(n=16)$ & $p$ value \\
\hline $\begin{array}{l}\text { Creatinine } \\
\text { MED (MIN-MAX) }\end{array}$ & $\begin{array}{c}0.8 \\
(0.8-0.9)\end{array}$ & $\begin{array}{c}0.9 \\
(0.7-1.0)\end{array}$ & $\begin{array}{c}0.9 \\
(0.8-1.0)\end{array}$ & $\begin{array}{c}0.9 \\
(0.7-1.0)\end{array}$ & NS \\
\hline $\begin{array}{l}\text { GFR }- \text { CKD-EPI } \\
M E \pm S D\end{array}$ & $110.7 \pm 10.6^{a}$ & $106.2 \pm 18.1$ & $95.4 \pm 17.5^{\mathrm{b}}$ & $91.6 \pm 18.9^{b, c}$ & 0.007 \\
\hline $\begin{array}{l}\text { Urea } \\
\mathrm{ME} \pm \mathrm{SD}\end{array}$ & $25.8 \pm 6.4$ & $29.6 \pm 9.6$ & $29.4 \pm 8.5$ & $31.5 \pm 8.0^{c}$ & NS \\
\hline $\begin{array}{l}\text { Serum Calcium (mg/dl) } \\
\mathrm{ME} \pm \mathrm{SD}\end{array}$ & $9.3 \pm 0.8$ & $9.1 \pm 0.7$ & $9.6 \pm 0.8$ & $9.1 \pm 0.7$ & NS \\
\hline $\begin{array}{l}\text { Serum Phosphorus (mg/dl) } \\
M E \pm S D\end{array}$ & $3.4 \pm 0.5$ & $3.2 \pm 0.7$ & $3.4 \pm 0.5$ & $3.6 \pm 0.6$ & NS \\
\hline $\begin{array}{l}\text { Serum Alkaline Phosphatase (U/l) } \\
\text { MED (MIN-MAX) }\end{array}$ & $\begin{array}{c}66.0^{\mathrm{a}} \\
(55.0-79.7)\end{array}$ & $\begin{array}{c}95.0 \\
(90.0-106.0)\end{array}$ & $\begin{array}{c}92.5 \\
(78.5-109.0)\end{array}$ & $\begin{array}{c}99.0 \\
(86.2-121.5)\end{array}$ & 0.043 \\
\hline $\begin{array}{l}\text { PTH (pg/dl) } \\
\text { MED (MIN-MAX) }\end{array}$ & $\begin{array}{c}24.5^{\mathrm{a}} \\
(15.3-29.9)\end{array}$ & $\begin{array}{c}41.1 \\
(27.5-55.3)\end{array}$ & $\begin{array}{c}35.0 \\
(22.1-46.2)\end{array}$ & $\begin{array}{c}36.8 \\
(29.2-56.1)\end{array}$ & 0.055 \\
\hline $\begin{array}{l}\text { Serum Vitamin D }(\mathrm{ng} / \mathrm{ml}) \\
\mathrm{ME} \pm \mathrm{SD}\end{array}$ & $40.9 \pm 14.2^{\mathrm{a}}$ & $34.2 \pm 12.9^{\mathrm{a}, \mathrm{b}}$ & $30.4 \pm 8.7^{b}$ & $30.6 \pm 10.2^{b}$ & 0.049 \\
\hline $\begin{array}{l}\text { Femur BMD }\left(\mathrm{g} / \mathrm{cm}^{2}\right) \\
\text { MED (MIN-MAX) }\end{array}$ & $0.9(0.8-0.9)$ & $0.9(0.8-0.9)$ & $0.8(0 .-0.9)$ & $0.8(0.7-1.0)$ & NS \\
\hline $\begin{array}{l}\text { Lumbar spine } \mathrm{BMD}\left(\mathrm{g} / \mathrm{cm}^{2}\right) \\
\mathrm{ME} \pm \mathrm{SD}\end{array}$ & $0.9 \pm 0.2$ & $1.0 \pm 0.1$ & $1.0 \pm 0.1$ & $1.0 \pm 0.2$ & NS \\
\hline $\begin{array}{l}\text { CTX-I (ng/ml) } \\
\text { MED (MIN-MAX) }\end{array}$ & $0.1(0.0-0.5)$ & $0.1(0.0-0.3)$ & $0.1(0.0-0.3)$ & $0.0(0.0-0.2)$ & NS \\
\hline $\begin{array}{l}\text { Bone Alkaline Phosphatase (U/l) } \\
\mathrm{ME} \pm \mathrm{SD}\end{array}$ & $19.7 \pm 15.0^{\mathrm{a}}$ & $37.6 \pm 20.0^{b}$ & $36.1 \pm 10.3^{b, c}$ & $25.4 \pm 18.0$ & 0.005 \\
\hline $\begin{array}{l}\text { Osteocalcin (ng/ml) } \\
\text { MED (MIN-MAX) }\end{array}$ & $\begin{array}{c}6.8^{\mathrm{a}} \\
(4.4-9.0)\end{array}$ & $\begin{array}{c}14.1^{\mathrm{b}} \\
(8.8-18.6)\end{array}$ & $\begin{array}{c}15.5^{c} \\
(10.3-23.1)\end{array}$ & $\begin{array}{c}16.5^{\mathrm{b}, \mathrm{c}} \\
(6.8-23.0)\end{array}$ & 0.005 \\
\hline
\end{tabular}

PLWHA: People living with HIV/AIDS; G1: PLWA antirretroviral therapy (ART)-naïve; G2: PLWHA under ART for less than 2 years; G3: PLWHA under ART for 2 to 10 years; G4: PLWHA on ART for more than 10 years. ME: Mean; SD: Standard Deviation; MED: Median; MIN-MAX: Minimum and Maximum; GFR: Glomerular Filtration Rate; CKD-EPI: Chronic Kidney Disease Epidemiology Collaboration; PTH: Parathormone; BMD: Bone Densitometry; CTX: C-terminal Telopepitid; NS: Not Significant. Statistical test used: Multiple Comparison (ANOVA) followed by Tukey-Kramer post hoc tests and Kruskal-Wallis. Distinct letters (a, b and c) represent statistical differences. 


\section{Bone diseases}

Several studies have reported greater bone loss with high rates of osteopenia and osteoporosis in PLWHA (Bonjoch et al., 2010; Brown and Qaqish, 2006; Ofotokun et al., 2016), which may be three times more common in this population, compared to uninfected individuals (Gallant et al., 2004; Harris and Brown, 2012; Kwak et al., 2019). In general, in this study, the prevalence of osteopenia/osteoporosis was high (53.2\%), a very similar result to that found by another Brazilian study, conducted by Pinto-Neto et al. (2011), whose prevalence was 54.7\%. However, as shown in Fig. 3, a curious fact observed here was the high frequency of these changes, found not only in G4 (62.5\%), in which it was expected due to the influence of ART, but also in G1 (63.7\%), a group of individuals still without treatment, while the other groups showed intermediate prevalence (G2, 36.4\% and G3, 53.0\%). In a way, this high occurrence in G1 can be explained by the fact that HIV itself induces an inflammatory state that can lead to bone loss through the promotion of osteoclastogenesis and bone resorption induced by inflammatory cytokines (Gallant et al., 2004).

In the pre-ART era, advanced HIV infection was associated with low levels of bone formation markers and high levels of bone resorption. However, with the start of therapy, increases in both markers were observed, indicating an increase in bone turnover (Brown et al., 2009; Kwak et al., 2019).

In this study, BMD and CTX levels were not different between groups. To further the analysis of bone changes, we investigated levels of phosphorus and calcium, which were also similar between groups, with levels of PTH, vitamin D, OC, total alkaline phosphatase (tALP) and BAP showing significant differences between groups. Thus, despite the high frequency of osteopenia in G1 and G4, greater bone involvement was evident in the groups undergoing ART, as the G1 individuals had lower levels of PTH, tALP, BAP and OC in relation to the other groups, in addition to higher levels of vitamin $\mathrm{D}$. These data are shown in Table 2.

It is worth mentioning that in Pearson's analysis, positive correlations were found between osteocalcin and the duration of therapy ( $p=0.05)$, especially with the use of PI $(p=0.004)$. The interference of this class of antiretroviral in osteoblastic differentiation was also demonstrated in a study by Hirakawa et al. (2017), whose change to integrase inhibitors normalized this profile. Similarly, Bonnet et al. (2013) also reported early BMD loss in patients who started a PI regimen, which was correlated with gain in fat mass by such individuals. However, active bone modeling was evident with all antiretroviral regimens, associated with low levels of vitamin D and hyperparathyroidism.

Contrary to our results, a decrease in BMD was reported in a longitudinal study conducted by Madeddu et al. (2015b), performed on PLWHA treated for a long period. However, these authors also associated more changes in those with PI, compared to those using NNRTI, emphasizing that the mechanism by which ART acts on the bone structure is still unclear, but that some hypotheses can be made about its direct action on bone remodeling and/or indirect action on the vitamin-D metabolism, thus aggravating bone loss due to HIV infection itself. Other studies have also shown that bone changes are more frequent in individuals under ART regimens containing tenofovir than in those in regimens without this drug Bolland et al., 2015; Stellbrink et al., 2010; Vlot et al., 2018). However, in this study, the specific drugs used by patients were not analyzed, but only the ART schemes/regimens.

In general, it was observed that the levels of PTH, a hormone responsible for regulating the levels of phosphorus and calcium in the body, were within normal limits (data not shown) in the studied population. Regarding vitamin D, most individuals had desirable levels, but more than $12 \%$ of patients on ART had insufficient levels of this marker, suggesting a likely influence of therapy on such reduction, which occurred mainly in patients using efavirenz. These results are in agreement with those found by Dao et al. (2011) and Brown and McComsey (2010), who associated vitamin-D deficiency with the use of this drug. Wohl et al. (2014) also noted that individuals on ART using efavirenz or rilpivirine had a significant decrease in vitamin-D levels 48 weeks after starting treatment.

There were no differences between groups regarding the risk of fractures in 10 years, as analyzed by the FRAX tool. It should be noted that FRAX was performed only on patients aged 40 years or older, which left us with a small number of individuals for analysis. However, our results are similar to those found in a systematic review and meta-analysis, in which it was suggested that both HIV infection and ART use are associated with a slight increase in the risk for fractures. However, the use of the FRAX tool for the HIV-infected population is not yet validated and is still under study (Shiau et al., 2013; Yin and Falutz, 2016).

In summary, $64 \%$ of patients studied here were dyslipidemics, $12.1 \%$ presented moderate and high-Framingham Risk Score and 20\% showed stage- 2 and stage- 3 renal alterations. All these changes were more expressive in those that had been using ART for a longer period of time. High prevalences of osteopenia and osteoporosis (53.2\%) were found, especially in the naïve group and in those under longer ART use; however, the first group had lower levels of tALP, BAP and osteocalcin, in addition to higher concentrations of vitamin D than the others. ART-naïve individuals also showed the lowest CPK levels.

It is worth mentioning this study had some limitations, such as its cross-sectional design, a small sample and a small sampled number of patients with FRAX results, since those under 40 years old were excluded.

\section{Conclusions}

Our study showed the possible contributory role of antiretrovirals in metabolic, cardiac, renal and bone changes in patients with ART adherence and undetectable VL, because we found a high prevalence of changes in the markers analized here, especially in people who have been using ART for a long time. These data reinforce the importance of an early diagnosis of such dysfunctions in PLWHA, as well as the approach to the management of these comorbidities, considering their associated factors.

\section{Conflict of interests}

The authors declare that they have no conflicts of interest.

\section{Ethical approval}

This study was approved by the Research Ethics Committees of the Botucatu Medical School (FMB/UNESP), and the whole research process followed the principles of the Helsinki Declaration.

\section{Informed consent}

Informed consent was obtained from all individual participants included in the study. 


\section{Role of the funding source}

São Paulo Research Foundation (FAPESP, Proc. 2016/154404) and Coordenação de Aperfeiçoamento de Pessoal de Nível Superior (CAPES).

\section{Acknowledgements}

We thank the patients for their participation and all the employees at the Specialized Outpatient Service for Infectious Diseases "Domingos Alves Meira" for their endeavors. We would also like to thank EAP/UNESP and Dr. José Eduardo Corrente, in particular, for his assistance with statistical analysis, and finally acknowledge the financial support provided by São Paulo Research Foundation (FAPESP, Proc. 2016/15440-4) and Coordenação de Aperfeiçoamento de Pessoal de Nível Superior (CAPES).

\section{References}

Balloca F, D’Ascenzo F, Gili S, Grosso Marra W, Gaita F (2017). Cardiovascular disease in patients with HIV. Trends Cardiovasc Med 27(8): 558-563. DOI: 10.1016/j.tcm.2017.06.005.

Bergersen BM, Sandvik L, Bruun JN, Tonstad S (2004). Elevated Framingham risk score in HIV-positive patients on highly active antiretroviral therapy: results from a Norwegian study of 72 subjects. Eur J Clin Microbiol Infect Dis 23(8): 625-30. DOI: 10.1007/s10096-004-1177-6.

Bestawros M, Chidumayo T, Blevins M, Canipe A, Bala J, Kelly P, et al. (2015). Increased systemic inflammation is associated with cardiac and vascular dysfunction over the first 12 weeks of antiretroviral therapy among undernourished, HIV-infected adults in Southern Africa. J AIDS Clin Res 6(3): 431. DOI: 10.4172/21556113.1000431.

Bijker R, Jiamsakul A, Uy E, Kumarasamy N, Ditango R, Chaiwarith R, et al. (2019). Cardiovascular disease-related mortality and factors associated with cardiovascular events in the TREAT Asia HIV Observational Database (TAHOD). HIV Med 20(3): 183-191. DOI: 10.1111/hiv.12687.

Bolland M, Grey A, Horne AM, Briggs SE, Thomas MG, EllisPegler RB, et al. (2006). Bone Mineral Density is not reduced in HIV infected Caucasian men treated with highly active antiretroviral therapy. Clin Endocrinol (Oxf) 65(2): 191-197. DOI: 10.1111/j.1365-2265.2006.02572.x.

Bolland M, Grey A, Reid IR (2015). Skeletal health in adults with HIV infection. Lancet Diabetes Endocrinol 3(1): 63-74. DOI: 10.1016/ S2213-8587(13)70181-5.

Bonjoch A, Figueras M, Estany C, Perez-Alvarez N, Rosales J, del Rio L, et al. (2010). High prevalence of and progression to low bone mineral density in HIV-infected patients: a longitudinal cohort study. AIDS 24(18): 2827-2833. DOI: 10.1097/ QAD.0b013e328340a28d.

Bonnet E, Ruidavets JB, Genoux A, Mabile L, Busato F, Obadia M, et al. (2013). Early loss of bone mineral density is correlated with a gain of fat mass in patients starting a protease inhibitor containing regimen: the prospective Lipotrip study. BMC Infect Dis 13:293. DOI: $10.1186 / 1471-2334-13-293$.

Bonotto EH, Guerchon G, Coelho PHL, Ribeiro CE, do Nascimento MM (2016). Prevalence of chronic kidney disease in HIV-positive patients followed up at the HC-UHPR. Rer Med UFPR 4(4): 167-172. DOI: 10.5380/rmu.v4i4.50646.

Brasil. Ministério da Saúde (2008). Secretaria de Vigilância em Saúde. Programa Nacional de DST e Aids. Recomendações para terapia anti-retroviral em adultos e adolescentes infectados pelo HIV 2007/2008. Documento preliminar. [online] [cit. 2020-11-07]. Available from: https://www.who.int/hiv/amds/ consenso_2008_brasil.pdf

Brasil, Ministério da Saúde (2018). Departamento de Vigilância, Prevenção e controle das IST, HIV/Aids e das Hepatites Virais. Protocolo Clínico e Diretrizes Terapêuticas para Manejo da
Infecção pelo HIV em Adultos. [online] [cit. 2020-11-07]. Available from: http://www.aids.gov.br/pt-br/pub/2013/protocolo-clinicoe-diretrizes-terapeuticas-para-manejo-da-infeccao-pelo-hiv-emadultos

Brasil, Ministério da Saúde (2019). Secretaria de Vigilância em Saúde. Programa Nacional de DST e Aids. Boletim epidemiológico de HIV e Aids. [online] [cit. 2020-11-07]. Available from: https:// antigo.saude.gov.br/images/pdf/2019/novembro/29/Boletim-IstAids-2019-especial-web.pdf

Brown TT, McComsey GA (2010). Association between initiation of antiretroviral therapy with efavirenz and decreases in 25-hydroxyvitamin D. Antivir Ther 15(3): 425-429. DOI: 10.3851/ IMP1502.

Brown TT, Qaqish RB (2006). Antiretroviral therapy and the prevalence of osteopenia and osteoporosis: a meta-analytic review. AIDS 20(17): 2165-2174. DOI: 10.1097/QAD.0b013e32801022eb.

Brown TT, McComsey GA, King MS, Qaqish RB, Bernstein BM, da Silva BA (2009). Loss of bone mineral density after antiretroviral therapy initiation, independent of antiretroviral regimen. J Acquir Immune Defic Syndr 51(5): 554-561. DOI: 10.1097/ QAI.0b013e3181adce44.

Cristelli MP, Trullàs JC, Cofán F, Rico N, Manzardo C, Ambrosioni J, et al. (2018). Prevalence and risk factors of mild chronic renal failure in HIV-infected patients: influence of female gender and antiretroviral therapy. Braz J Infect Dis 22(3): 193-201. DOI: 10.1016/j.bjid.2018.05.001.

Crum-Cianflone N, Ganesan A, Teneza-Mora N, Riddle M, Medina S, Barahona I, Brodine S (2010). Prevalence and factors associated with renal dysfunction among HIV Infected patients. AIDS Patient Care STDS 24(6): 353-360. DOI: 10.1089/apc.2009.0326.

d'Arminio Monforte A, Diaz-Cuervo H, De Luca A, Maggiolo F, Cingolani A, Bonora S, et al. (2019). Evolution of major nonHIV-related comorbidities in HIV-infected patients in the Italian Cohort of Individuals, Naïve for Antiretrovirals (ICONA) Foundation Study cohort in the period 2004-2014. HIV Med 20(2): 99-109. DOI: 10.1111/hiv.12683.

Dai L, Liu A, Zhang H, Wu H, Zhang T, Su B, et al. (2019). Impact of Lopinavir/Ritonavir and Efavirenz-Based Antiretroviral Therapy on the Lipid Profile of Chinese HIV/AIDS Treatment-Naïve Patients in Beijing: A Retrospective Study. Curr HIV Res 17(5): 324. DOI: $10.2174 / 1570162 X 17666191025115508$.

Dao CN, Patel P, Overton ET, Rhame F, Pals SL, Johnson C, et al. (2011). Low vitamin D among HIV-Infected adults: prevalence of and risk factors for low vitamin D levels in a cohort of HIVinfected adults and comparison to prevalence among adults in US general population. Clin Infect Dis 52(3): 396-405. DOI: 10.1093/ cid/ciq158.

Deeks S (2011). HIV Infection, Inflammation, Immunosenescence, and Aging. Ann Rev Med 62: 141-155. DOI: 10.1146/annurevmed-042909-093756.

Déti EK, Thiébaut R, Bonnet F, Lawson-Ayayi S, Dupon M, Neau D, et al. (2010). Prevalence and factors associated with renal impairment in HIV-infected patients, ANRS C03 Aquitaine Cohort, France. HIV Med 11(5): 308-317. DOI: 10.1111/j.14681293.2009.00780.x.

Dorjee K, Choden T, Baxi SM, Steinmaus C, Reingold AL (2018). Risk of cardiovascular disease associated with exposure to abacavir among individuals with HIV: A systematic review and meta-analyses of results from 17 epidemiologic studies. Int J Antimicrob Agents 52(5): 541-553. DOI: 10.1016/j. ijantimicag.2018.07.010.

Duprez DA, Kuller LH, Tracy R, Otvos J, Cooper DA, Hoy J, et al. (2009). Lipoprotein particle subclasses, cardiovascular disease and HIV infection. Atherosclerosis 207(2): 524-529. DOI: 10.1016/j. atherosclerosis.2009.05.001.

Egger M, Junghans C, Friis-Møller N, Lundgren JD (2001). Highly active antiretroviral therapy and coronary heart disease: the need for perspective. Aids 15: S193-S201. DOI: 10.1097/00002030200100005-00023.

Faludi AA, de Oliveira Izar MC, Saraiva JFK, Chacra APM, Bianco HT, Afiune Neto A, et al. (2017). Atualização da Diretriz Brasileira de Dislipidemias e Prevenção da Aterosclerose - 2017. Arq Bras Cardiol 109(2 Suppl. 1): 1-76. DOI: 10.5935/abc.20170121. 
Francisci D, Pirro FM, Schiaroli E, Mannarino MR, Cipriani S, Bianconi V, et al. (2019). Maraviroc Intensification Modulates Atherosclerotic Progression in HIV-Suppressed Patients at High Cardiovascular Risk. A Randomized, Crossover Pilot Study. Open Forum Infect Dis 6(4): ofz112. DOI: 10.1093/ofid/ofz112.

Friis-Møller N, Sabin CA, Weber R, d'Arminio Monforte A, ElSadr WM, Reiss P, et al. (2003). Combination antiretroviral therapy and the risk of myocardial infarction. N Engl J Med 349(21): 1993-2003. DOI: 10.1056/NEJMoa030218.

Fukumoto AECG, Oliveira CC, Tasca KI, Souza LR (2013). Evolution of patients with aids after cART: clinical and laboratory evolution of patients with aids after 48 weeks of antiretroviral treatment. Rev Inst Med trop S. Paulo 55(4): 267-273. DOI: 10.1590/S003646652013000400008.

Gallant JE, Staszewski S, PozniK AL, DeJesus E, Suleiman JMAH, Miller MD, et al. (2004). Eficacy and safety of tenofovir DF VS stavudine in combination therapy in antiretroviral-naive patients: a 3-year randomized trial. JAMA 292(2): 191-201. DOI: 10.1001/ jama.292.2.191.

Guaraldi G, Orlando G, Zona S, Menozzi M, Carli F, Garlassi E, et al. (2011). Premature age-related comorbidities among HIV-infected persons compared with the general population. Clin Infect Dis 53(11): 1120-1126. DOI: 10.1093/cid/cir627.

Hajjar LA, Calderaro D, Yu PCh, Giuliano I, de Oliveira Lima EM, et al. (2005). Cardiovascular manifestations in patients infected with the human immunodeficiency virus. Arq Bras Cardiol 85(5): 363-377. DOI: 10.1590/S0066-782X2005001800013.

Harris VW, Brown TT (2012). Bone loss in the HIV-infected patient: evidence, clinical implications, and treatment strategies. J Infect Dis 205(Suppl. 3): S391-398. DOI: 10.1093/infdis/jis199.

Hidalgo JA, Florez A, Agurto C, Pinedo Y, Ayarza R, Rodriguez L, et al. (2018). Metabolic and Cardiovascular Comorbidities Among Clinically Stable HIV Patients on Long-Term ARV Therapy in Five Ambulatory Clinics in Lima-Callao, Peru. Open AIDS J 12: 126-135. DOI: 10.2174/1874613601812010126.

Hirakawa H, Gatanaga H, Ochi H, Fukuda T, Sunamura S, Oka S, et al. (2017). Antiretroviral Therapy Containing HIV Protease Inhibitors Enhances Fracture Risk by Impairing Osteoblast Differentiation and Bone Quality. J Infect Dis 215(12): 18931897. DOI: $10.1093 /$ infdis/jix246.

Kanis JA, on behalf of the World Health Organization Scientific Group (2007). Assessment of osteoporosis at the primary healthcare level. Technical Report. Sheffield, UK: WHO Collaborating Centre. [online] [cit. 2017-03-01]. Available from: https://www.shef.ac.uk/FRAX/tool.aspx? country=55

Kanis JA, McCloskey EV, Johansson H, Oden A, Melton LJ, 3rd, Khaltaev N (2008). A reference standard for the description of osteoporosis. Bone 42(3): 467-475. DOI: 10.1016/j. bone.2007.11.001.

Krikke M, Tesselaar K, van den Berk GEL, Otto SA, Freriks LH, van Lelyveld SFL, et al. (2018). The effect of switching protease inhibitors to raltegravir on endothelial function, in HIV-infected patients. HIV Clin Trials 19(2): 75-83. DOI: 10.1080/15284336.2018.1455366.

Kwak MK, Lee EJ, Park JW, Park SY, Kim B-J, Kin TH, et al. (2019). CD4 T cell count is iversely associated with lumbar spine bone mass in HIV-infected men under the age of 50 years. Osteoporos Int 30(7): 1501-1510. DOI: 10.1007/s00198-019-04942-7.

Lugon JR (2009). Chronic Kidney Disease in Brazil: A Public Health Problem. J Bras Nefrol 31: 2-5.

Madeddu G, De Socio GVL, Ricci E, Quirino T, Orofino G, Carenzi L, et al. (2015a). Muscle symptoms and creatine phosphokinase elevations in patients receiving raltegravir in clinical practice: results from the SCOLTA project long-term surveillance. Int J Anticrob Agents 45(3): 289-294. DOI: 10.1016/j. ijantimicag.2014.10.01.

Madeddu G, Spanu A, Solinas P, Babudieri S, Calia GM, Lovigu C, et al. (2015b). Different impact of NNRTI and PI-including HAART on bone mineral density loss in HIV-infected patients. Eur Rev Med Pharmacol Sci 19(23): 4576-4589.

Menezes AM, Torelly J, Jr., Real L, Bay M, Poeta J, Sprinz E (2011). Prevalence and Risk Factors Associated to Chronic Kidney Disease in HIV-Infected Patients on HAART and Undetectable Viral
Load in Brazil. PLoS ONE 6(10): e26042. DOI: 10.1371/journal. pone.0026042.

Mgogwe J, Semvua H, Msangi R, Mataro C, Kajeguka D, Chilongola J (2012). The evolution of haematological and biochemical indices in HIV patients during a six-month treatment period. Afr Health Sci 12(1): 2-7.

Mocroft A, Kirk O, Gatell J, Reiss P, Gargalianos P, Zilmer K, et al. (2007). Chronic renal failure among HIV-1-infected patients. AIDS 21(9): 1119-1127. DOI: 10.1097/QAD.0b013e3280f774ee.

National Kidney Foundation (2011). Frequent asked questions about GFR estimates. [online] [cit. 2019-05-02]. Available from: http:// www.kidney.org/professionals/kls/pdf/12-10-4004_KBB_FAQs_ AboutGFR-1.pdf

Neaton JD, Neuhaus J, Emery S (2010). Soluble biomarkers and morbidity and mortality among people infected with HIV: summary of published reports from 1997 to 2010. Curr Opin HIV Aids 5(6): 480-490. DOI: 10.1097/ COH.0b013e32833ed75d.

Ofotokun I, Titanji K, Vunnava A, Roser-Page S, Vikulina T, Villinger F, et al. (2016). Antiretrovieal therapy induces a rapid increase in bone resorption that is positively associated with the magnitude of immune reconstitution in HIV infection. AIDS 30: 405-414. DOI: 10.1097/QAD.0000000000000918.

Palella FJ, Jr., Phair JP (2011). Cardiovascular disease in HIV infection. Curr Opin HIV/AIDS 6(4): 266-271. DOI: 10.1097/ COH.0b013e328347876c.

Pinto Neto LF da S, das Neves MB, Ribeiro-Rodrigues R, Page K, Miranda AE (2013). Dyslipidemia and fasting glucose impairment among HIV patients three years after the first antiretroviral regimen in a Brazilian AIDS outpatient clinic. Braz J Infect Dis 17(4): 438-443. DOI: 10.1016/j.bjid.2012.12.006.

Pinto Neto LF da S, Ragi-Eis S, Vieira NFR, Soprani M, Neves MB, Ribeiro-Rodrigues R, Miranda AE (2011). Low bone mass prevalence, therapy type, and clinical risk factors in an HIVinfected Brazilian population. J Clin Densitom 14(4): 434-439. DOI: 10.1016/j.jocd.2011.06.004.

Ramana KV, Rao R, Kandi S, Singh PA, Kumar VBP (2013). Elevated activities of serum lactate dehydrogenase in human immunodeficiency virus sero-positive patients in highly active antiretroviral therapy era. 2(3): 162-166. DOI: $10.4103 / 2277-$ 8632.117180.

Shiau S, Broun EC, Arpadi SM, Yin MT (2013). Incident fractures in HIV-infected individuals: a systematic review and meta-analysis. AIDS 27(12): 1949-1957. DOI: 10.1097/ QAD.0b013e328361d241.

Smith CJ, Ryom L, Weber R, Morlat P, Pradier C, Reiss P, et al. (2014). Trends in underlying causes of death in people with HIV from 1999 to 2011 (D:A:D): a multicohort collaboration. Lancet 384(9939): 241-248. DOI: 10.1016/S0140-6736(14)60604-8.

Souza SJ, Luzia LA, Santos SS, Rondó PHC (2013). Lipid profile of HIV-infected patients in relation to antiretroviral therapy: a review. Rev Assoc Med Bras 59(2): 186-198. DOI: 10.1016/j. ramb.2012.11.003.

Stellbrink H-J, Orkin C, Arribas JR, Compston J, Gerstoft J, Van Vijngaerden E, et al. (2010). Comparison of changes in Bone Density and turnover with abacavir-lamivudine versus tenofovir-entricitabine in HIV-infected adults: 48-week results from the ASSERT study. Clin Infect Dis 51(8): 963-972. DOI: $10.1086 / 656417$.

Suligoi B, Virdone S, Taborelli M, Frova L, Grande E, Grippo F, et al. (2018). Excess mortality related to circulatory system diseases and diabetes mellitus among Italian AIDS patients vs. nonAIDS population: a population-based cohort study using the multiple causes-of-death approach. BMC Infect Dis 18(1): 428. DOI: 10.1186/s12879-018-3336-x.

Tasca KI, Caleffi JT, Correa CR, Gatto M, de Camargo CC, Mendes MB, et al. (2016). The Initial Months of Antiretroviral Therapy and Its Influence on AGEs, HMGB1, and sRAGE Levels in Asymptomatic HIV-Infected Individuals. Mediators Inflamm 2016: 2909576. DOI: 10.1155/2016/2909576.

Triant VA (2013). Cardiovascular disease and HIV infection. Curr HIV/AIDS Rep 10(3): 199-206. DOI: 10.1007/s11904-0130168-6. 
UNAIDS - Joint United Nations Programme on HIV/AIDS (2015). Fast-Track: accelerating action to end the AIDS epidemic by 2030. [online] [cit. 2019-25-22]. Avaliable from: <https://www. unaids.org/sites/default/files/media_asset/201506_JC2743_ Understanding_FastTrack_en.pdf>

Vlot MC, Grijsen ML, Prins JM, de Jongh RT, de Jonge R, den Heijer M, Heijboer AC (2018). Effect of antiretroviral therapy on bone turnover and bone mineral density in men with primary HIV-1 infection. PLoS One 13(3): e0193679. DOI: 10.1371/ journal.pone.0193679.

Vos AG, Chersich MF, Klipstein-Grobusch K, Zuithoff P, Moorhouse MA, Lalla-Edward ST, et al. (2018). Lipid levels, insulin resistance and cardiovascular risk over 96 weeks of antiretroviral therapy: a randomised controlled trial comparing low-dose stavudine and tenofovir. Retrovirology 15(1): 77. DOI: 10.1186/ s12977-018-0460-z.

Wand H, Calmy A, Carey DL, Samaras K, Carr A, Law MG, et al. (2007). Metabolic syndrome, cardiovascular disease and type 2 diabetes mellitus after initiation of antiretroviral therapy in HIV infection. AIDS 21(18): 2445-2453. DOI: 10.1097/ QAD.0b013e3282efad32.

Wilson PWF, D’Agostino RB, Levy D, Belanger AM, Silbershatz B, Kannel WB (1998). Prediction of coronary heart disease using risk factor categories. Circulation 97: 1937-1947. DOI: 10.1161/01. CIR.97.18.1837.

Wohl DA, Orkin C, Doroana M, Pilotto JH, Sungkanuparph S, Yeni P, et al. (2014). Change in vitamin D levels and risk of sever vitamin D deficiency over 48 weeks among HIV-1-infected, treatment-naïve adults receiving rilpivirine or efavirenz in a phase III trial (ECHO). Antivir Ther 19: 191-200. DOI: 10.3851/ IMP2721.

Worm SW, Sabin C, Weber R, Reiss P, El-Sadr W, Dabis F, et al. (2010). Risk of myocardial infarction in patients with HIV infection exposed to specific individual antiretroviral drugs from the 3 major drug classes: the data collection on adverse events of anti-HIV drugs (D:A:D) study. J Infect Dis 201(3): 318-330. DOI: 10.1086/649897.

Yin MT, Falutz J (2016). How to predict risk of fracture in HIV? Curr Opin HIV AIDS 11(3): 261-267. DOI: 10.1097/ COH.0000000000000273.

Young J, Weber R, Rickenbach M, Furrer H, Bernasconi E, Hirschel B, et al. (2005). Lipid profiles for antiretroviral-naïve patients starting PI- and NNRTI-based therapy in the Swiss HIV Cohort Study. Antiv Ther 10(5): 585-591. 